\title{
ESPAÇOS DE HIPERTEXTO, MÍDIA E CULTURA EM O MEZ DA GRIPPE E OUTROS LIVROS, DE VALÊNCIO XAVIER
}

Marta da Piedade Ferreira*

RESUMO:

Este texto busca mostrar em 0 mez da grippe e outros livros, de Valêncio Xavier, alguns aspectos das apropriações da mídia pela narrativa literária, perfazendo uma mesclagem intersemiótica, e a estruturação hipertextual como uma nova forma de estrutura romanesca.

PALAVRAS-CHAVE: Valêncio Xavier, hipertexto, intersemiose, metamídia, tecnologia.

O mez da grippe e outros livros, de Valêncio Xavier, uma coletânea de novelas e contos, editado em 1998, reune os seus quatros primeiros livros: 0 mez da grippe, Maciste no inferno, 0 mistério da prostituta japonesa \& Mimi-Nashi-Oichi, 0 minotauro e o livro de contos inéditos 13 mistérios + 0 mistério da porta aberta.

Valêncio Xavier que se limitava a uma divulgação restrita e regional, a partir dessa publicação, passou a ser reconhecido nacionalmente, despontando no cenário da crítica literária brasileira, chamando a atenção, principalmente, para a inovação formal que caracteriza seus textos.

Joca Reiners Terron (1999: 5-9), o considera "um dos mais intrigantes e originais escritores brasileiros em atividade", na atualidade. Já, o escritor Ricardo Aleixo afirma que a forma como Valêncio Xavier estrutura as suas narrativas tem a ver com a sua formação profissional, por ele ser um sujeito polígrafo que atuou em várias ocupações ligadas à escrita e por ter adquirido uma notável destreza no manejo da palavra:

|* Mestre em Letras: Literatura e outros Sistemas Semióticos (Ârea de concentração: Teoria da Literatura), 2004. 


\section{EMTESE}

Belo Horizonte, v. 9, p. I-28I, dez. 2005

Como quem não quer nada além de se divertir, Xavier testa os limites de cada gênero, sempre à procura da forma mais adequada a cada assunto, mas age como quem transita em um ambiente próprio, fora da literatura reconhecida como tal, esforçando-se por nos fazer crer que seu conhecimento é "de almanaque", não erudito. (Aleixo, 1998: 3).

Essa habilidade Valêncio Xavier nos apresenta em 0 mez da grippe $e$ outros livros e nos coloca em contato com variados textos coerentes com um tempo de mídias tecnológicas. Através da declaração do próprio autor nos inteiramos de como ele concebe os seus textos:

Você vê cartazes, placas, com desenhos, cores, símbolos e palavras. Letras imóveis formando palavras, que se movimentam andando no ônibus, na rua vazia. Ouve sons, do motor, do silêncio depois que o ônibus passa. Um cão caminha apressado, grita (ou late) suas palavras para a velha na janela, que retruca: 'Passa, guapeca!'. A menina sai pela porta verde, a velha procura prever: 'Vá com Deus!'. Palavras, imagens e sons, que podemos pôr no papel. Para mim, as imagens têm o mesmo peso que as palavras. Eu não vivo no passado, mas o passado vive em mim. E no futuro eu não penso, não posso prevê-10. Talvez isso que eu ponho no papel, escrevo, talvez isso seja o meu passado e talvez seja o meu futuro, em que não penso (grifo nosso). (Xavier, 1999: 5-9).

Na obra de Valêncio Xavier coexistem múltiplas formas de expressão. A presença de imagens, palavras e sons retirados do cotidiano, de fatos acontecidos - ou passíveis de acontecer -, misturados a leituras do comportamento humano, compõem as narrativas instigantes, intersemióticas e "grafoliterárias"1 do escritor.

Para Décio Pignatari (1998, 4-8), a novela que dá título ao livro, 0 mez da grippe, abriu um novo caminho para a escritura - caracteriza-a especialmente como "modelar" - e afirma que o escritor "não fez romance ilustrado, nem ilustração romanceada", mas abriu um caminho inovador para a escritura, em particular, para a escritura gráfica. Considera Valêncio Xavier o "nosso primeiro escritor romancista gráfico, depois do grande e frustrado Raul Pompéia de 0 ateneu" (Pignatari, 1998: 4-8).2

Pignatari (2001: 6) também nos diz que "Xavier se soma aos mistérios decifráveis da literatura" 20 anos depois de sua obra pioneira, 0 mez da grippe. Para ele, a edição bem feita de 0 mez da grippe e outros livros, com o principal da produção grafoliterária de Valêncio Xavier, contribuiu para ver o seu percurso decifrável e trazer uma boa repercussão do trabalho do escritor no mercado editorial. Assim, Valêncio Xavier obteve êxito na confirmação de todo seu trabalho correspondente aos anos anteriores e na divulgação de outros textos. 
Sobre o reconhecimento do escritor pela crítica no cenário literário brasileiro, Carlos Graieb, em "Para ver e ler", considera que a Valêncio Xavier caberia o chavão do "ilustre desconhecido". Graieb o chama de ilustre "porque alguns dos críticos mais festejados do país, como Boris Schnaiderman, Flora Süssekind, Wilson Martins e Décio Pignatari insistem em seu valor e sua capacidade de inovar" (Graieb, 1998: 153-154), e de desconhecido, em vista de somente ter editado suas obras até aquela ocasião, setembro de 1998, em editoras independentes.

Referindo-se ainda ao seu fazer literário, ao falar sobre seu apelido "Frankenstein de Curitiba", que The foi atribuido pelo poeta e editor Joca Reiners Terron, Valêncio Xavier (1998: 4-1) afirma: "Acho ótimo o apelido. 0 doutor Frankenstein pegava pedaços de cadáveres e juntava as coisas. Eu faço literatura com pedaços de coisas". 0 autor refere-se, aí, à intersemiose da escritura de seus textos, a inserção concomitante de desenhos, lendas, texto poético, jornais, publicidades, fotogramas e fotografias.

\section{APROPRIAÇÕES DA MÍDIA PELO TEXTO LITERÁRIO XAVIERIANO}

0 universo da mídia que refere-se aos meios de comunicação de massa impressos, visuais, audiovisuais, publicitários - encontra-se presente na narrativa xavieriana através de imagens fac-similares de notícias e anúncios de jornais, fotografias e fotogramas. A respeito da importância do emprego da imagem em sua narrativa o escritor assevera que para ele a "imagem e a palavra têm o mesmíssimo peso" (Cruz, 1998: 4-8).

Sobre o aspecto da redundância, da informatividade e da complementaridade entre imagem e texto, Lucia Santaella e Winfried Nöth, em $A$ imagem, citam Kalverkämper que apresenta três possíveis casos:

(1) a imagem é inferior ao texto e simplesmente o complementa, sendo, portanto, redundante. (...) (2) A imagem é superior ao texto e, portanto, o domina, já que ela é mais informativa do que ele. (...) (3) Imagem e texto 


\section{EMTESE}

Belo Horizonte, v. 9, p. I-28I, dez. 2005

têm a mesma importância. A imagem é, nesse caso, integrada ao texto. A relação texto-imagem se encontra aqui entre redundância e informatividade. 0 caso da equivalência entre 0 texto e imagem é descrito como complementaridade ([por] Molitor et al. 1989: 21-29). [E] Spillner (1982:96) fala de determinação recíproca. A vantagem da complementaridade do texto com a imagem é especialmente observada no caso em que conteúdos de imagem e de palavra utilizam os variados potenciais de expressão semióticos de ambas as mídias (Cf. Titzmann 1990: 380). (Santaella e Nöth, 2001: 54-55).

As imagens das narrativas de Valêncio Xavier possuem a abertura proporcionada pela mensagem visual. Os textos e as imagens possuem a mesma importância, encerram em si um valor semântico, e também funcionam, em seu texto, no conjunto das construções narrativas, como uma direção oferecida aos olhos do leitor, para que este possa obter um certo sentido, muitas vezes plausível, com direções dúbias. Os textos e as imagens podem ser lidos em separado e, também, no conjunto.

Em 0 mez da grippe, as imagens fac-similares de anúncios e notícias de jornais compõem o eixo dos dois assuntos centrais da história: a gripe espanhola, em Curitiba, e a Primeira Guerra Mundial. 0 teor das notícias, manchetes e anúncios específicos daquele período, disponibilizados em ordem cronológica e em forma de diário, e que também lembram a disposição de um almanaque, imprimem o ritmo e 0 desenvolvimento na narrativa. É como uma representação da realidade dos dias e, ou dos acontecimentos da época. Ao empregar a mídia na construção das narrativas, o autor também passa a idéia de um simulacro da realidade retratada, impresso com intensidade, através da descrição de pormenores desse cotidiano.

Roland Barthes (1984: 13) nos diz que a fotografia reproduz ao infinito o que aconteceu uma vez, e repete mecanicamente algo que não poderá mais existir. As fotografias em 0 mez da grippe retratam uma realidade que se desdobra sob inúmeras formas de representação.

Já a publicidade da época ilustra a narrativa com mensagens que descrevem os usos e costumes dos habitantes da Curitiba de 1918, numa situação de calamidade provocada pela gripe espanhola; ao mesmo tempo, de acordo com a sua disposição na narrativa, tais mensagens dialogam com outras situações e histórias.

Em Maciste no inferno, fotogramas de um filme simulam a sala de um cinema com um filme em exibição. Dentre os espectadores se encontra um homem, que aproveita a oportunidade para tentar "bolinar" uma mulher. As imagens provenientes 
dos fotogramas, dispostas numa certa seqüência, produzem um efeito contextual através de suas próprias imagens, mas o texto verbal funciona como uma confirmação da seqüência imagética.

Tanto em 0 mez da grippe como em Maciste no inferno os elementos da mídia têm uma forte expressão. Eles expressam uma história, uma síntese de um relato, em partes, e junto aos variados elementos, num conjunto onde se integram visual e textual, constroem uma narrativa maior. 0 texto e imagem se encontram numa relação complementar (Santaella e Nöth, 2001: 55).

Nas ilustrações dos demais textos xavierianos, a imagem dirige o leitor a um significado escolhido antecipadamente (Santaella e Nöth, 2001: 55). A referência parte do texto para a imagem. Exemplo disso, podemos encontrar em 13 mistérios + 0 mistério da porta aberta, onde o texto prevalece sobre as ilustrações, as fotografias e as publicidades.

0 uso de elementos iconográficos nas narrativas de Valêncio Xavier pode ser classificado, como sugere Flora Süssekind (2002: 267), como metamídia, sobretudo por tomarem "por interlocutora a linguagem do espetáculo, a mídia". Para ela, o emprego dos meios de comunicação na prosa literária, misturados aos personagens ficcionais, se transforma numa metamídia. Ela cita o uso do jornal e da propaganda em 0 mez da grippe, e do cinema em Maciste no inferno, onde o autor toma de "procedimentos e figuras da mídia, mas dando-1hes um outro rendimento" (Süssekind, 2002: 268).

\section{HIPERTEXTO - LABIRINTO: UMA RELEITURA DA TRADIÇÃO ROMANESCA}

Pierre Lévy, em As tecnologias da inteligência, nos informa que foi Vannevar Bush, em 1945, quem divulgou a idéia de hipertexto pela primeira vez, no artigo "As we may think" (Lévy, 1999: 28). Bush se inspirou no processo reticular do exercício da inteligência e propõe um dispositivo chamado Memex, com o objetivo de "mecanizar a classificação e a seleção por associação paralelamente ao princípio 


\section{EMTESE}

Belo Horizonte, v. 9, p. I-28I, dez. 2005

da indexação clássica" (Lévy, 1999: 28). As informações como imagens, sons e textos, seriam condensadas em microfilmes e em fitas magnéticas para serem acessadas simultaneamente por uma tela, como a de uma televisão. A solicitação de uma primeira informação permitiria a identificação e a união com outras, estabelecendo-se uma conexão possível de ser recuperada toda vez que um botão fosse acionado. Essas conexões idealizadas por Bush, ainda não classificadas como hipertexto, seriam para auxiliar a memória do cientista e ajudar na pesquisa e na elaboração de conhecimentos.

0 termo hipertexto foi inventado por Theodore Nelson, na década de sessenta, para explicar o processo da escrita e da leitura não linear em um sistema de informática e objetivou manter uma rede para acesso em tempo real às informações literárias e científicas mundiais, e que constituiria uma grande "biblioteca" denominada Xanadu. 0 sistema imaginado por Nelson armazenaria todos os documentos disponiveis e seria utilizado para a criação de novos documentos e apreciação dos já existentes, sem redundâncias e sem destruir informações.

Os projetos Memex ou Xanadu não chegaram às dimensões universais imaginadas por seus idealizadores devido à impossibilidade da programação de bancos de dados nas proporções pretendidas.

Numa perspectiva técnica, Pierre Lévy destaca, que

um hipertexto é um conjunto de nós ligados por conexões. Os nós podem ser palavras, páginas, imagens, gráficos ou partes de gráficos, seqüências sonoras, documentos complexos que podem eles mesmos ser hipertextos. Os itens de informação não são ligados linearmente, como em uma corda de nós, mas cada um deles, ou a maioria, estende suas conexões em estrelas, de modo reticular. Navegar em um hipertexto significa portanto desenhar um percurso em uma rede que pode ser tão complicada quanto possível. Porque cada nó pode, por sua vez, conter uma rede inteira (Lévy, 1999: 33).

0 acesso à informação será definido a partir de uma pesquisa, que se estabelece, inicialmente, através de qualquer ponto que, posteriormente, determinará e formará uma rede de informações através de ligações variadas, de forma não linear. 0 hipertexto é formado por uma variada rede de interfaces redobradas, possíveis/ passiveis de serem acessadas simultaneamente.

De acordo com Pierre Lévy (1999: 25-26), seis princípios básicos do hipertexto explicam a sua atuação: metamorfose - heterogeneidade - multiplicidade e encaixe das escalas - exterioridade - topologia - mobilidade dos centros. 
Considerando tais princípios, é plausível afirmar que as narrativas de Xavier apresentam uma estrutura hipertextual. Em todas as histórias há vários núcleos narrativos que se desdobram em outros pela proximidade, heterogeneidade, metamorfose e simultaneidade, trata-se de núcleos móveis que sugerem a possibilidade de virtualizar novos núcleos.

A novela 0 mez da grippe seria, nesse sentido, um hipertexto. A mesclagem dos variados signos iconográficos proporciona uma multiplicidade de informações visuais e textuais, de forma simultânea e heterogênea e uma leitura não linear de modo que o leitor poderá iniciar seu contato com o texto/imagem de qualquer parte da narrativa. 0 autor afirmou, em entrevista, que 0 mez da grippe pode ser lido como um jornal, onde o leitor, numa leitura não linear, desloca o olhar em várias direções (Xavier, 1999: 5-9). 0 leitor poderá ir de uma manchete para uma publicidade, verificar uma gravura ou uma fotografia, sem se deter em um ponto, construindo e refazendo, ao mesmo tempo, a sua rede de leitura. Poderá começar a sua leitura nas páginas iniciais, no meio ou no final, em qualquer parte. Os vários signos são como links que abrem conexões com outros. Cada um possui uma informação, um valor.

Nessa perspectiva, Ricardo Aleixo (1998: 3), afirma que a novela 0 mez da grippe - é "um verdadeiro 'ovo de Colombo' intersígnico", onde o leitor será autor do percurso que fará nesse labirinto de signos entrecruzados. Entretanto, 0 autor proporciona direções dúbias em algumas situações, e favorece a permanência de um enigma a ser descoberto e a busca de sentidos para o texto, o que o torna, dessa forma, um múltiplo e desdobrado objeto de recepção.

Também, em Maciste no inferno, o leitor poderá formar sua rede de leitura, mas terá um universo menor de signos iconográficos, em comparação com a novela 0 mez da grippe, como nas demais narrativas de 0 mez da grippe e outros livros.

Na novela 0 minotauro, cada página funciona como um capítulo de uma história "labiríntica" que se passa em um hotel de baixa categoria. 0 assunto de alguns capítulos são retomados em outros com alterações e em nova perspectiva. Em outros capítulos, por exemplo, no quarto e no nono, compostos por diálogos, tem-se a idéia de que os acontecimentos são simultâneos ao que se passa com o homem e a 


\section{EMTESE}

Belo Horizonte, v. 9, p. I-28I, dez. 2005

mulher loira, no quarto e nos corredores daquele hotel. Esses acontecimentos parecem formar um labirinto hipertextual, micro-relatos inter-relacionáveis.

Nos contos de 13 mistérios + 0 mistério da porta aberta, a maioria das narrativas traz desenhos, ilustrações, fotografias e publicidades que mantêm uma conexão com a história.

Valêncio Xavier ao construir suas narrativas intercalou variados assuntos e, para isto, fez uso do recorte e da colagem. De acordo com Antoine Compagnon (1996: 31), em 0 trabalho da citação, quando lemos e escrevemos realizamos um ato de citação.

Dessa forma, o autor é como um artesão ao recortar e colar, para construir o seu texto. 0 trabalho da mesclagem de vários signos, também se compara ao de um bricoleur, citado por Lévi-Strauss, em 0 pensamento selvagem. E assim nos faz considerar que Valêncio Xavier, a partir das características do funcionamento do hipertexto, inovou na forma da apresentação da leitura de um livro, e também ao realizar vărias mesclagens entre muitos sistemas semióticos, com uma idéia hipertextual, utilizando o formato originado do códice (codex). 0 livro se transforma em livromáquina hipertextual, ganhando a estrutura básica do hipertexto, o que permite uma leitura múltipla, não linear, por meio de aberturas de telas.

0 mez da grippe e outros livros, na sua forma de apresentação interna, acompanha o formato das novas tecnologias e transfere essas inovações para o texto do livro que conhecemos e ainda manuseamos.

NOTAS:

1. Denominação dada por Décio Pignatari.

2. De acordo com Carlos Graieb, Oswald de Andrade, teria sido um dos primeiros autores brasileiros a pensar a literatura numa relação com o desenho, ao utilizar versos e desenhos em seu Primeiro caderno do aluno de poesia. 
ABSTRACT :

It is pointed out in this essay that some media aspects were used by the literary narrative in 0 mez da grippe $e$ outros livros, from Valêncio Xavier, mixing up intersemiotic and hypertextual structure, as one new kind of romanesque work.

KEY WORDS: Valêncio Xavier, hypertext, intersemiotic, metamedia, technology.

\section{REFERÊNCIAS BIBLIOGRÁFICAS}

COMPAGNON, A. Tesoura e cola; Ablação; Grifo; Acomodação; Solicitação; A leitura em ação; 0 homem da tesoura; Uma canonização metonímica; Enxerto; Reescrita; 0 trabalho da citação. In: ___ O trabalho da citação. Trad. Cleonice P. B. Mourão. Belo Horizonte: Editora UFMG, 1996. p. 11-34.

CRUZ, Leonardo. Xavier faz literatura com recortes de jornal. Folha de S. Paulo. São Paulo, 01 out. 1998. Ilustrada, Livro, p. 4-8.

FERREIRA, Marta da Piedade. Espaços de hipertexto, mídia e cultura em 0 mez da grippe e outros livros, de Valêncio Xavier. Universidade Federal de Minas Gerais, 2004. 144 p. (Dissertação, Mestrado em Teoria da Literatura).

GRAIEB, Carlos. Para ver e ler. Revista Veja, São Paulo, ano 31, n. 10, p. 153-154, 16 set. 1998.

- Literatura brasileira. Revista Veja, São Paulo, ano 34, n. 10, p. 156-157, 14 mar. 1999.

LÉVY, P. As tecnologias da inteligência. Trad. C. I. da Costa. Rio de Janeiro: Ed. 34, 1999.

MACHADO, Cassiano Elek. Frankenstein de Curitiba mostra nova cria literária. Folha de S. Paulo, São Paulo, 20 mar. 1999. Ilustrada, p. 4-1.

PIGNATARI, Décio. Mez da grippe abre novo caminho para a escritura. Folha de S. Paulo, São Paulo, 01 out. 1998. Ilustrada, Livro, p. 4-8.

- Xavier se soma aos mistérios decifráveis da literatura. Folha de S. Paulo, São Paulo, 12 maio. 2001. Ilustrada, Livros-Lançamentos, p. E6.

SANTAELLA, L. NÖTH, W. In: Imagem. São Paulo: Iluminuras, 2001.

XAVIER, Valêncio. "Mez da grippe" revela escritor polígrafo. O Tempo, Belo Horizonte, p. 3, 3 out. 1998. Entrevista concedida a Ricardo Aleixo.

- O mez da grippe e outros livros. São Paulo: Companhia das Letras, 1998.

- 0 Frankenstein de Curitiba. Revista Cult, São Pau10, n. 20, p. 5-9, mar. 1999. Entrevista concedida a Joca Reiners Terron. 


\section{EMTESE}

Belo Horizonte, v. 9, p. I-28I, dez. 2005

XAVIER, Valêncio. 0 grande circo freak de Valêncio Xavier. Meu 70 dia - uma novella-rébus. São Paulo: Ciência do Acidente, 1999. Entrevista concedida a Joca Reiners Terron.

\section{VERBETES:}

BRICOLAGE. In: CHILILERS, J.; HENTZI, G. The Columbia Dictionary of Modern Literary Cultural Criticism. New York: Columbia University Press, 1995. p. 34.

MÍdIA. In: BARBOSA, G.; RABAÇA; C. A. Dicionário de comunicação. Rio de Janeiro: Campus, 1950. Nova Edição revista e atualizada, $2^{a}$ tiragem, 2001. p. 490.

WORLD WIDE WEB. In: BARBOSA, G.; RABAÇA C. A. Dicionário de comunicação. Rio de Janeiro: Campus, 1950. Nova ed. rev. atual. $2^{\text {a }}$ tiragem, 2001. p. 770. 